\title{
Correlation of functional and radiological outcome of management of distal end radiud fractures using a trinary surgical treatment
}

\author{
Siddalingamurthy.$G^{1}$, Sheshagiri ..$^{2, *}$ Shreyas. M.J ${ }^{3}$ \\ ${ }^{\mathbf{1}}$ Associate Professor, ${ }^{2}$ Assistant Professor, ${ }^{3}$ Resident, Dept. of Orthopaedics J.S.S. Medical College and Hospital, Mysore, \\ Karnataka, India
}

*Corresponding Author:

Email: drsheshu@yahoo.com

\begin{abstract}
The approach of surgical management of distal intraarticular radial fractures is gaining popularity in the current scenario, and there is no concluding evidence as to which method of surgery fares better than the other, this article attempts to compare the radiological and functional outcome of trinary surgical treatment (percutaneous pinning, ligamentotaxis and plate and screw fixation) for distal end radius intraarticular fractures.

Materials and Methods: It was a prospective study involving 90 patients who presented with distal end intra-articular radius fractures, each of these patients were randomly assigned to be treated by ligamentotaxis and plate and screw fixation, percutaneous pinning, $(n=30)$ each who were operated between January 2016 to May 2017 and their data with respect to functional and radiological outcome were collected over one year.

Results: In this research paper out of the 90 patients, the excellent scores were in 13 patients accounting $14.4 \%$, good scores $47.8 \%$ in 43 patients and fair and the poor scores $25.6 \%$ and $12.2 \%$ functionally were seen in 23 and 11 patients respectively, The Cramer s V value was not found significant, the values noted are 0.84. A significant association between groups and Volar tilt, Radial angle and Radial shortening. Cramer's V was found to be significant ( $\mathrm{P}$ - value 0.0001) radiologically.

The outcome with respect to radiology and the function was measured using werley and gartland scoring and the lidstorm scoring system.

Conclusion: In this study the open reduction and internal fixation with plate and screws gave a restored radiological outcome compared to the ligamentotaxis and percutaneous pinning group but the functional outcome remained the same in all the three treatment groups.
\end{abstract}

Keywords: Distal radius Intra articular fractures, Volar locking plate, Percutaneous Kirshner wire fixation, Ligamentotaxis.

\section{Introduction}

The epidemiology and management of distal radial intraarticular fractures in unknown in Asian population but accounts to about accounts to about $18 \%$ in adults ${ }^{1}$ and about $22.4 \%$ in children in urban scenario ${ }^{2}$ and constitutes for $1 / 6$ of the fractures in the emergency department and portrays for 4.88 times the incidence in women than in men. ${ }^{3}$

There is a trinary distribution of fractures in the general population where the fractures are seen in paediatric age group, then in the middle age group and then in 4th and 5th decades of age with more in women population. 4

There are various configurations of the fractures with involvement of various columns, these patterns demands supplementary forms of fixations to maintain the anatomy and radiological parameters if not catered will lead to poor results. ${ }^{3}$

Among all the available surgical modalities, which fares better is controversial, as various other factors should also be taken in to consideration such as fracture displacement, dorsal comminution, osteoporosis etc ${ }^{5}$ patients compliance and demands ${ }^{6}$ as well.

The distal end radius fractures are in the centre of orthopedicians acquaintance the rate of unsatisfactory results is high hence a perspicuous approach should be employed.
The modality of supplementary pinning was found to be better than casting, ${ }^{7}$ ligamentotaxis and the percutaneous pinning, versus locking plates the later achieved better anatomical results with special emphasis on early recovery and faster return to function after the injury. ${ }^{8}$

The aim of this study is to analyse the radiological and functional results with the trimodal surgical treatment, as there is very less literature comparing all the three modalities. ${ }^{8}$

\section{Materials and Methods}

The prospective randomized comparative study was done at JSS hospital a tertiary care referral hospital in Mysore between Jan 2016 to May 2017, a series of 90 patients who had distal end intraarticular fractures were selected and detailed history, clinical data, $x$ rays from pictures archiving and communication system (PACS), were collected and randomly assigned using a random number generator to the three treatment groups, out of which 30 patients each, were treated by ligamentotaxis, open reduction internal fixation with plates and screws and closed percutaneous pinning respectively.

The cases who had failed closed reduction, displaced fractures, fractures with metaphyseal comminution, polytrauma patients, open fractures, bilateral injuries were included in the study and those 
patients who were skeletally immature, patients unwilling to consent for study, pts who are medically unfit for proposed surgical treatment were excluded from the study.

All surgeries were done under all aseptic precautions following the guidelines of $\mathrm{AO}$ for percutaneous wire fixation, safe planes for placement of pins for ligamentotaxis and modified Henry approach for plate and Screw fixation, by the consultants of the orthopaedic unit using $\mathrm{C}$ arm assistance under general anaesthesia or ultras ound guided brachial block.

Implants used were Kirshner wires (size $2 \mathrm{~mm}-3.5$ $\mathrm{mm}$ ), Schanz pins (size $2.5 \mathrm{~mm}-3.5 \mathrm{~mm}$ ), connecting rods, clamps, ' $\mathrm{T}$ ' locking buttress plate, oblique ' $\mathrm{T}$ ' locking plate and $3.5 \mathrm{~mm}$ cortical screws / locking screws, tourniquet was used in cases where plating surgery was chosen.

After surgery, the limb was immobilized in cuff and collar sling, parenteral antibiotics were given on the day of surgery and oral antibiotics for another week. Follow up was done for 16 weeks from the day of surgery.

Active finger, elbow and shoulder exercises were encouraged post operatively to promote circulation, avoid oedema, stiffness of joints, followed by 4-6 physiotherapy sessions. Post-operative check x-ray was taken, and a note of radial height, radial angulation and palmar intraarticular incongruity were made using PACS.

Clinical assessment for range of motion was reviewed at weekly intervals using a goniometer.

Check x-rays were taken at 6 weekly intervals after surgery $\mathrm{x}$ ay measurements for anatomical alignment noted using PACS.
K-wire wires were removed 6-8 weeks interval. External fixator was removed between 4-6 weeks interval. No additional splintage was provided.

After removal, wrist motion was measured by a goniometer with elbow flexed 90 degrees and grip assessed using dynamometer, comparing with uninjured side again it was followed by physiotherapy sessions for 1 week.

These patients were scored using werley and gartland scoring ${ }^{9}$ lidstorm scoring (table 1$)^{10}$ to know the functional and radiological outcome respectively.

Statistical Analysis: The data obtained were fed in to spss software version and Microsoft excel tables obtained, the descriptive procedure displays univariate summary statistics for several variables in a single table and calculates standardized values (z scores). Variables can be ordered by the size of their means (in ascending or descending order), alphabetically, or by the order in which the researcher specifies.

Following descriptive statistics were employed in the present study-mean, Standard deviation, frequency and percent.

Crosstabs (Cramer's V): The Crosstabs procedure forms two-way and multiway tables and provides a variety of tests and measures of as sociation for two-way tables. The structure of the table and whether categories are ordered determine what test or measure to use. Cramer's V test was employed in the present study.

One-Way Anova: The One-Way Anova procedure produces a one-way analysis of ${ }^{9}$ variance for a quantitative dependent variable by a single factor (independent) variable. Analys is of variance is used to test the hypothesis that several means are equal. This technique is an extension of the two-sample $t$ test.
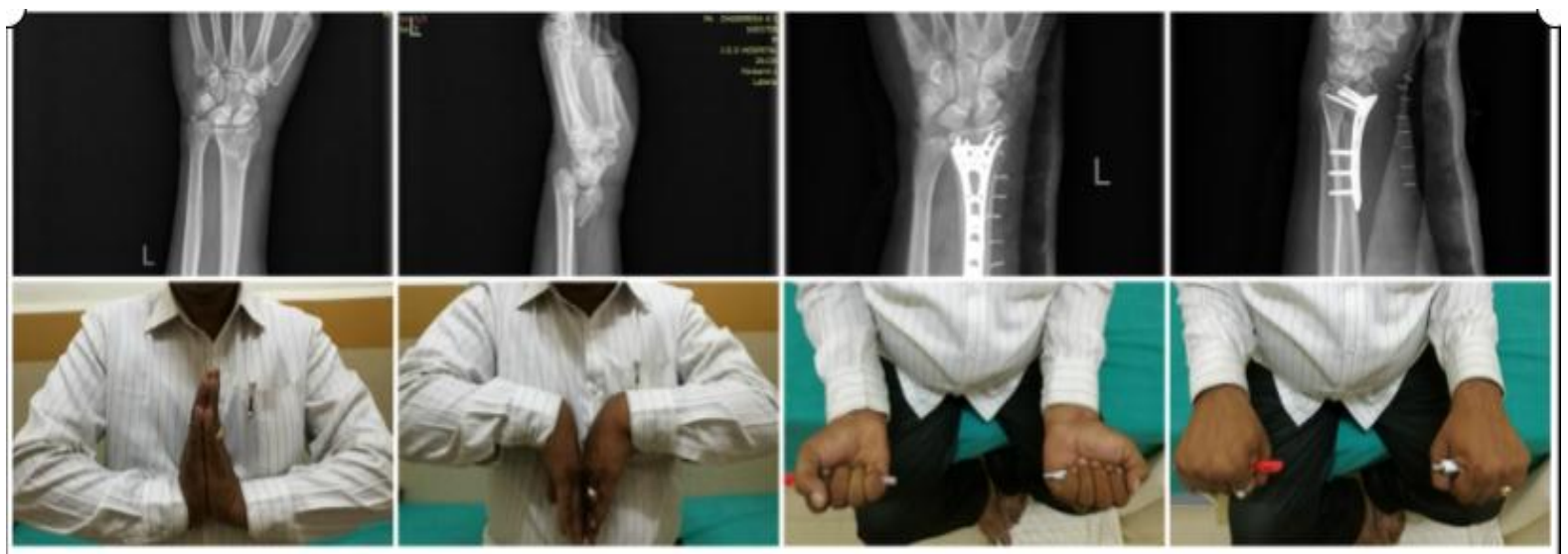

Fig. 1: Plating image 

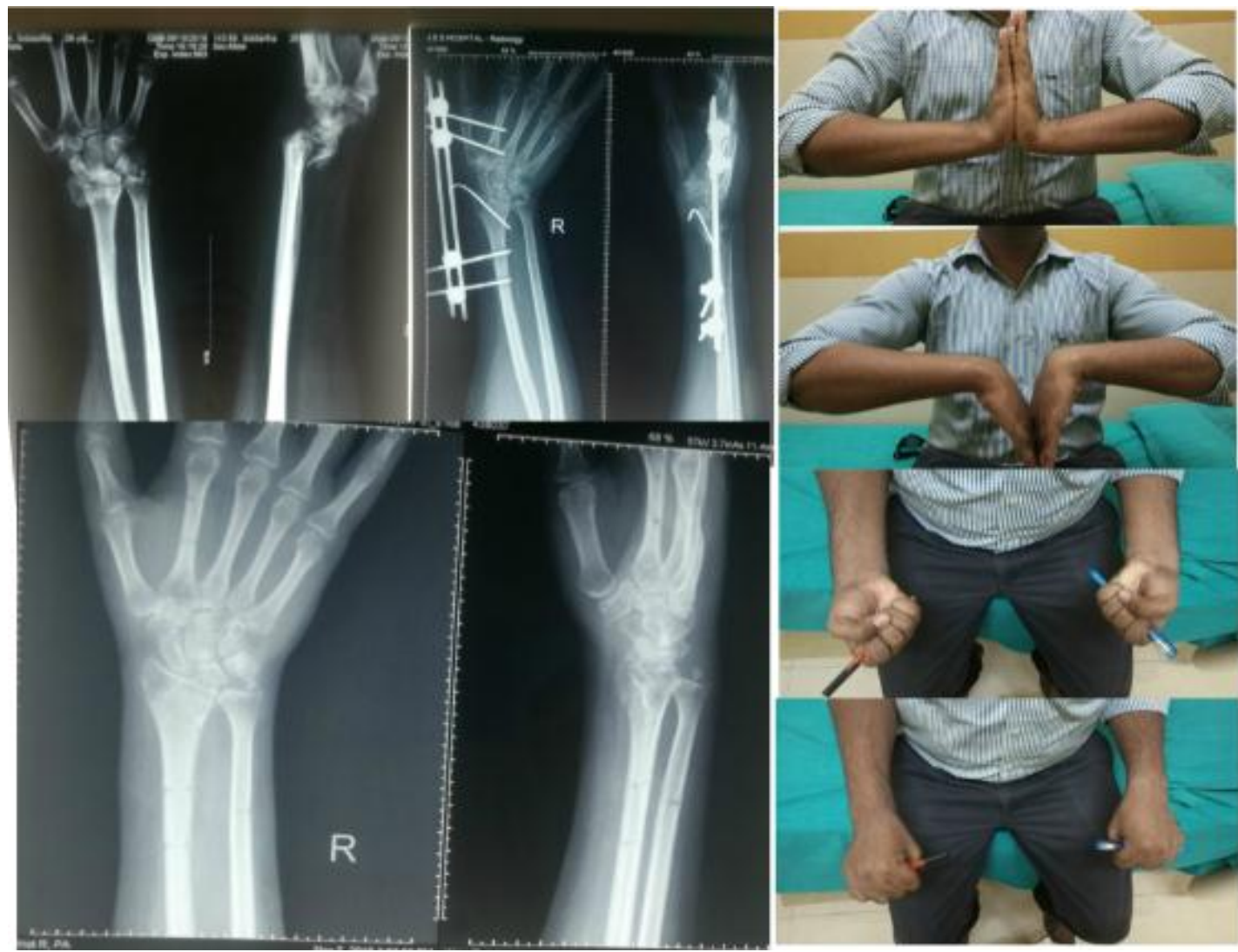

Fig. 2: Ligamentotaxis image

\section{Results}

In this series Out of 90 patients, 37(41.1\%) patients were between $19-30$ years, $23(25.6 \%)$ between 31-40 years, $17(18.9 \%)$ between $41-50$ years, $13(14.4 \%)$ above 50 . The fractures were common in the age group of 19-30 years of age the average age being $40 \mathrm{yrs}$.

69 (76.7\%) were males and 21(23.3\%) were female, with male preponderance. A significant association between groups and distribution of gender values. Cramer's V value of 0.257 was found to be significant at 0.050 level.

$43(47.8 \%)$ patients had right extremity involvement and 47(52.2\%) patient involved left hand. there were $56(62.2 \%)$ patients with road traffic accidents and $34(37.8 \%)$ patients fell on their outstretched hand.

The no of patients as per Frykman classification were type III 19(21.1\%), type IV26 (28.9\%), type V
10(11.1\%), type VI 26(28.9\%), type VII 7(7.8\%), type VIII $2(2.2 \%)$.

A significant association between groups and Frykman classification values. Cramer's V value of 0.340 was found to be significant at 0.023 level. Out of the 90 cases $82(91.1 \%)$ of the fractures were of Closed Type and $8(8.9 \%)$ were Open Type injuries.

The Mean immobilization time in the Plating group was 6 weeks, ligamentotaxis group was 6.5 weeks, and the closed pinning group was 6.7 weeks.

Complications in our series were 1 case with pin tract infection, 2 cases with pin loosing and 1 case with EPL irritation.

The Functional outcome in our series, 13(14.4\%) patients had excellent result. 43(47.8\%) patients had good result. $23(25.6 \%)$ patients had fair result and 11(12.2\%) patients had poor result. (Table 1, Graph 1)

No significant association between groups and functional assessment Cramer's V value of 0.184 was found to not significant at 0.412 level.

Table 1: Table showing distribution of Grade (Functional outcome) and treatment

\begin{tabular}{|c|c|c|c|c|c|c|}
\hline \multicolumn{7}{|c|}{ Crosstab } \\
\hline & & & & group & & Total \\
\hline & & & $\begin{array}{l}\text { Lig } \\
\end{array}$ & Plate & $\mathrm{K}$ wire & \\
\hline \multirow{4}{*}{ grade } & \multirow{2}{*}{ Excellent } & Count & 5 & 6 & 2 & 13 \\
\hline & & $\%$ within group & $16.7 \%$ & $20.0 \%$ & $6.7 \%$ & $14.4 \%$ \\
\hline & \multirow{2}{*}{ Good } & Count & $\overline{15}$ & 16 & 12 & 43 \\
\hline & & $\%$ within group & $50.0 \%$ & $53.3 \%$ & $40.0 \%$ & $47.8 \%$ \\
\hline
\end{tabular}




\begin{tabular}{|c|c|c|c|c|c|c|}
\hline \multirow{3}{*}{ fair } & Count & 7 & 6 & 10 & 23 \\
\cline { 2 - 6 } & & $\%$ within group & $23.3 \%$ & $20.0 \%$ & $33.3 \%$ & $25.6 \%$ \\
\cline { 2 - 6 } & \multirow{2}{*}{ poor } & Count & 3 & 2 & 6 & 11 \\
\cline { 2 - 6 } & $\%$ within group & $10.0 \%$ & $6.7 \%$ & $20.0 \%$ & $12.2 \%$ \\
\hline \multirow{2}{*}{ Total } & Count & 30 & 30 & 30 & 90 \\
\cline { 2 - 6 } & $\%$ within group & $100.0 \%$ & $100.0 \%$ & $100.0 \%$ & $100.0 \%$ \\
\hline
\end{tabular}

Graph 1: Showing distribution of Grade (Functional outcome) and treatment

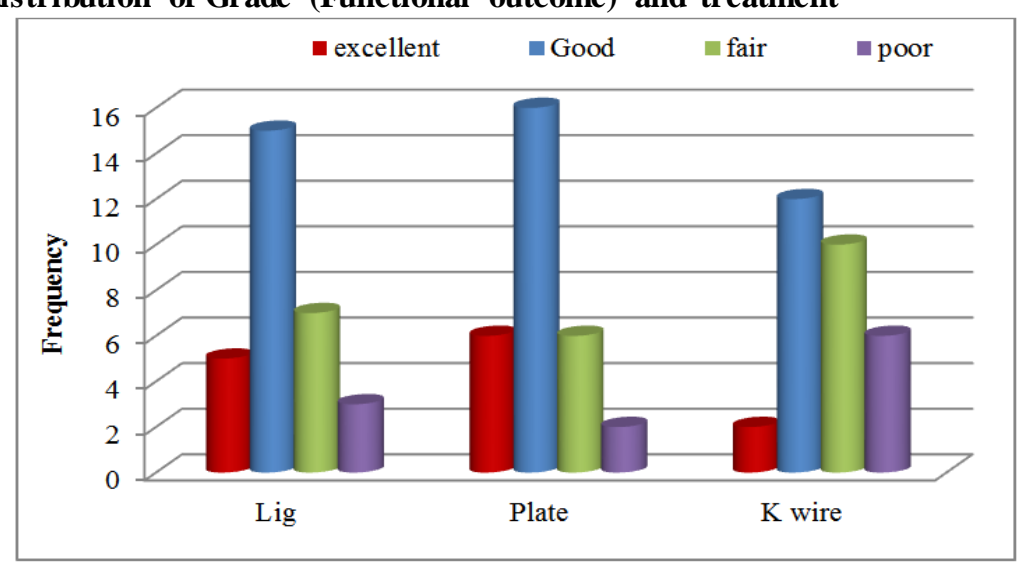

The radiological outcome assessed using the lidstorm criteria, ${ }^{10}$ the open reduction internal fixation with plate and screws group showed excellent outcome and the ligamentotaxis and percutaneous $\mathrm{k}$ wire fixation has similar Good outcome (graph 2,3,4) in view of the recent advances in surgeries and newer $\mathrm{C}$ arm usage in all cases addressing at getting a better radiological outcome, we also assessed the radiological incongruity where the articular incongruity was less than $1 \mathrm{~mm}$ in 56.67 patients, and 40 patients and 50 patients in the plating and percutaneous pinning and ligamentotaxis group respectively suggesting the plating technique had better outcome (Graph 2,3,4 and Table 2)

\section{Graph 2: Mean dorsal angulation/ tilt in degree}

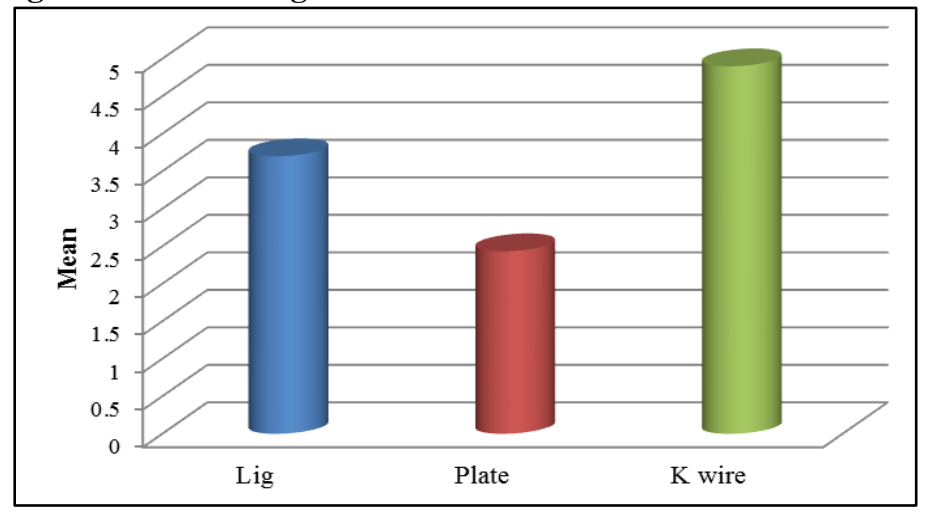

Graph 3: Radial Shorting-mm

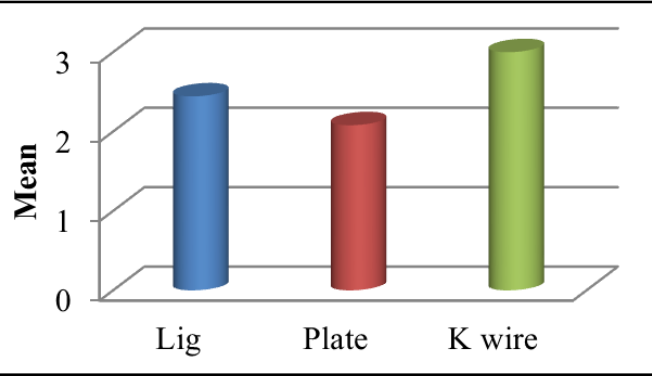

Graph 4: Radial Angle-degree

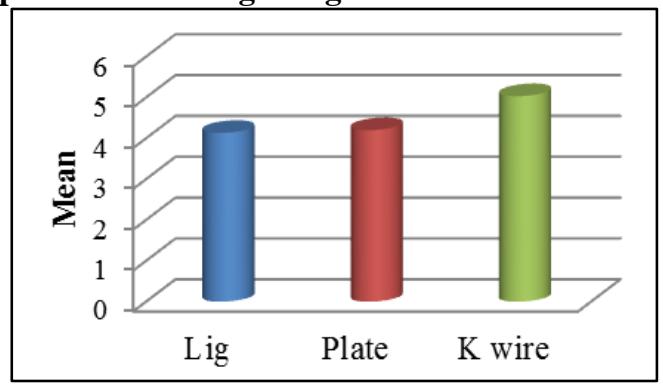


A significant association between groups and Volar tilt, Radial angle and Radial shortening. Cramer's V was found to be significant (P- value 0.0001).

Table 2: Lindstrom Criteria

\begin{tabular}{|l|c|c|c|c|}
\hline & $\begin{array}{c}\text { Residual } \\
\text { deformity }\end{array}$ & $\begin{array}{c}\text { Loss of palmar } \\
\text { tilt in degrees }\end{array}$ & $\begin{array}{c}\text { Radial } \\
\text { shortening in } \\
\text { millimeter }\end{array}$ & $\begin{array}{c}\text { Loss of radial } \\
\text { deviation in } \\
\text { degrees }\end{array}$ \\
\hline Excellent & No significance & 0 & $<3$ & 5 \\
\hline Good & Slight & $1-10$ & $3-6$ & $5-9$ \\
\hline Fair & Moderate & $11-14$ & $7-11$ & $10-14$ \\
\hline Poor & Severe & At least 15 & At least 12 & $>11$ \\
\hline
\end{tabular}

\section{Discussion}

The distal end intraarticular fractures need anatomical reduction restoring the angles for optimum results functionally, there are variety of surgical management options, but we choose the three options closed percutaneous pinning and ligamentotaxis and open reduction and internal fixation with locked plate and screws as the three modalities of treatment.

In our study we look in to radiological and functional outcome separately to put forward our observations, Applying the lidstorm criteria ${ }^{10}$ the radiological outcomes in the plating group were excellent, and the ligamentotaxis and percutaneous $\mathrm{k}$ wire fixation group remained good which emphasises that since the use of $\mathrm{C}$ arm in all cases and aiming at anatomical reduction the outcomes still remained excellent and $\operatorname{good}^{11}$ but lately there was loss of reduction in the ligamentotaxis and $\mathrm{k}$ wire fixation groups making it statistically significant. ${ }^{12}$

Functional Outcome measures -Fixation of comminuted articular fractures of distal radius with multiple Kirschner wires alone are insufficient to withstand forces across the fracture site and to prevent fracture collapse. However, percutaneous pinning alone can be used in fractures with limited comminution with good results and few complications.

Ligamentotaxis neutralises the compressive forces generated across the wrist joint. It provides efficient rigidity until bony healing occurred, thus allowing realignment of severely comminuted fractures. Although the ligamentotaxis can favourably affect articular surface tilting, severe fracture displacement and significant metaphyseal defects require additional modalities. There was a loss of reduction radiologically in the external fixation group compared to the plate group. $^{12}$

In comparative studies, Plate and screw fixation for treatment of intra articular fractures of distal radius gives statistically significantly better radiological outcome than treatment with ligamentotaxis and percutaneous pinning alone. ${ }^{13}$

There are many outcome measures described in the literature ${ }^{14}$ but we choose the modified werley and gartland scoring system ${ }^{9}$ to include the grip strength and pronation. ${ }^{15}$
In our study the open reduction and plating has shown satisfactory result that lead to high rate of return to work, high level of patient satisfaction and low rate of complications, even thought there are a lot of variables ${ }^{16}$ in this study but there is no statistically significant difference in functional outcome.

The limitation of the study being we randomised the patients in to three groups regardless of the fracture pattern or the degree of comminution which might affect the outcome and the sample size and study period are also less which requires further research.

Since we have lot of factors like the patient factors, fractures patterns ${ }^{17}$ dictating the choice of surgery ${ }^{11}$ and implant choice in management of distal radial fractures, we consider an meticulous approach to distal forearm fracture treatment using an analytical objective in solving problems. ${ }^{6}$

\section{Conclusion}

We looked in to the fact prospectively which treatment options regardless of the fracture pattern or the degree of comminution is better in terms of functional and radiological results, we arrive at the following conclusions open reduction and internal fixation with locked plate and screw gave radiologically and functionally better results immediately, the ligamentotaxis group fared a little better functionally as well as radiologically than percutaneous $\mathrm{k}$ wire fixation, but on long term there was no difference in the functional outcome regardless of the choice of surgery.

\section{References}

1. Sebastin SJ, Chung KC. An Asian Perspective on the Management of Distal Radius Fractures. Hand Clin. 2012 May;28(2):151-6.

2. Nellans KW, Kowalski E, Chung KC. The Epidemiology of Distal Radius Fractures. Hand Clin. 2012 May;28(2):113-25.

3. Khan JI, Hussain FN, Mehmood T, Adil O. A comparative study of functional outcome of treatment of intra articular fractures of distal radius fixed with percutaneous Kirschner's wires vs T-plate. PakJ Med Sci. 2017;33(3):709-13.

4. Singer BR, McLauchlan GJ, Robinson CM, Christie J. Epidemiology of fractures in 15,000 adults: the influence of age and gender. J Bone Joint Surg Br. 1998 Mar;80(2):243-8. 
5. Lichtman DM, Bindra RR, Boyer MI, Putnam MD, Ring D, Slutsky DJ, et al. Treatment of distal radius fractures. $J$ Am Acad Orthop Surg. 2010 Mar;18(3):180-9.

6. Koshkin AB, Sergeev SV, Matveev VS, Grishanin OB. Distal forearm fractures: the analytical approach for treatment. Ortop Traumatol Rehabil. 2008 Aug;10(4):324-30.

7. al AT et. Unstable extra-articular fractures of the distal radius: a prospective, randomised study of immobilisation in a cast versus supplementary percutane... - PubMed NCBI [Internet]. [cited 2018 Apr 19]. Available from: https://www.ncbi.nlm.nih.gov/pubmed/15911669.

8. Rozental TD, Blazar PE, Franko OI, Chacko AT, Earp BE, Day CS. Functional outcomes for unstable distal radial fractures treated with open reduction and internal fixation or closed reduction and percutaneous fixation. A prospective randomized trial. J Bone Joint Surg Am. 2009 Aug;91(8):1837-46.

9. Gartland JJ, Werley CW. Evaluation of healed Colles' fractures. J Bone Joint Surg Am. 1951 Oct;33-A(4):895907.

10. Lidstrom A. Fractures of the distal end of the radius. A clinical and statistical study of end results. Acta Orthop Scand Suppl. 1959;41:1-118.

11. Kapoor H, Agarwal A, Dhaon BK. Displaced intraarticular fractures of distal radius: a comparative evaluation of results following closed reduction, external fixation and open reduction with internal fixation. Injury. 2000 Mar 1;31(2):75-9.

12. Dicpinigaitis $\mathrm{P}$, Wolinsky $\mathrm{P}$, Hiebert R, Egol K, Koval K, Tejwani N. Can external fixation maintain reduction after distal radius fractures? J Trauma. 2004 Oct;57(4):84550 .

13. Geller L, Bernstein M, Carli A, Berry G, Reindl R, Harvey E. Efficacy of different fixation devices in maintaining an initial reduction for surgically managed distal radius fractures. Can J Surg J Can Chir. 2009 Oct;52(5):E161-166.

14. Changulani M, Okonkwo U, Keswani T, Kalairajah Y. Outcome evaluation measures for wrist and hand - which one to choose? Int Orthop. 2008 Feb;32(1):1-6.

15. Kwok IHY, Leung F, Yuen G. Assessing Results after Distal Radius Fracture Treatment. Geriatr Orthop Surg Rehabil. $2011 \mathrm{Jul} ; 2(4): 155-60$.

16. Bland JM, Altman DG. Statistical methods for assessing agreement between two methods of clinical measurement Lancet Lond Engl. 1986 Feb 8;1(8476):307-10.

17. Batra S, Gupta A. The effect of fracture-related factors on the functional outcome at 1 year in distal radius fractures. Injury. 2002 Jul 1;33(6):499-502. 